\title{
Revisiting the Improvement of Respiratory System Protection of Mining Workers
}

\author{
Cheberyachko S*, Deryugin 0, Tretyak 0 and Pustovoi D \\ Dnipro University of Technology, Ukraine
}

ISSN: 2578-0255

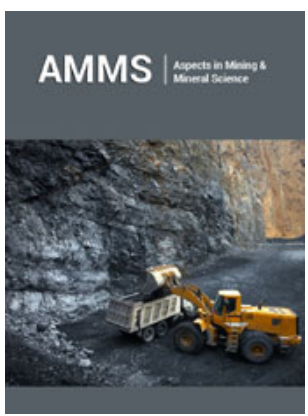

*Corresponding author: Cheberyachko Serhiy, Doctor of Technical Sciences, Dnipro University of Technology, Ukraine

Submission: 䀺 August 12, 2019

Published: 傮September 16, 2019

Volume 3 - Issue 3

How to cite this article: Cheberyachko S, Deryugin 0, Tretyak 0 and Pustovo D. Revisiting the Improvement of Respiratory System Protection of Mining Workers. Aspects Min Miner Sci.3(3). AMMS.000569.2019.

DOI: 10.31031/AMMS.2019.03.000569

Copyright@ Cheberyachko Serhiy, This article is distributed under the terms of the Creative Commons Attribution 4.0 International License, which permits unrestricted use and redistribution provided that the original author and source are credited.

\begin{abstract}
The analysis of respiratory protective device use efficiency has shown the substantial limitations of quality assessment for respirators. This results in potential hazard of excessive influence of harmful particulate pollutants on employees. To prevent occupational diseases development, it is extremely important that employers are motivated to improve labour conditions. Not least important is development of requirements to the biomonitoring procedure and conditions, as well as selection, testing and users training for individual respiratory protective devices use as based on the modern science development. The elimination of hazard class based only in providing the employees with individual respiratory protective devices is not scientifically substantiated and inadmissible way.
\end{abstract}

Keywords: Dust mask; Protection factor; Dust load; Pneumoconiosis

\section{Introduction}

Imperfect technological processes and equipment result in pollution of air with harmful substances in working zone area. In cases the maximum allowable concentration (MAC) of harmful substances is exceeded and it is impossible to reduce it to safe level by taking technical measures the use of individual respiratory protective devices (IRPD) is recommended. According to [1] the staff should be provided with respirators. The selection of the proper respirator type is regulated by [2]. The basic conformity criterion of protective equipment and its operation conditions is preponderance of its protective properties over the value of air contamination factor, i.e. the value ratio of particulate pollutants concentration and MAC. The reference documents describe a range of criteria for protective properties assessment of IRPD as follows:

a) Assigned Protection Factor (APF) shows the level of protection predicted to be obtained at the workplace for $95 \%$ of properly taught and trained workers using the IRPD which is functioning properly and is fitted properly;

b) Nominal Protection Factor (NPF) is the value obtained from the maximum value of general penetration factor set by the proper Standard for the separate class of IRPD;

c) Workplace Protection Factor (WPF) is the ratio of concentration of harmful substance in the breathing zone and under the mask.

It is recommended that employers use efficient certified IRPD to provide the guaranteed protection of workers from harmful particulate pollutants. Thus, the issue of IRPD efficiency assessment for particular conditions becomes urgent. It is common that high protection level of workers is based on the following issues:

d) quality of IRPD set by producer;

e) the proper IRPD selection substantiated by anthropometric characteristic of workers' faces and operating conditions;

f) workers teaching and training to use the IRPD.

\section{Problems of verification of protective properties filtering respirators}

The quality testing for respirators is carried out by means of application of correspondence modules according to the Technical Regulations for Individual Protective Devices. Filtering devices for respiratory protection belong to the third category, so they are assessed according to B module (Technical Regulations for Modules of Correspondence Assessment). The 
procedure consists in expert evaluation of technical documents and trial of one or some critical parts of product sample with respect to the proper standards. The latter are represented by a range of regulations describing requirements to trial procedure and quality indicators (EN 140:2004, EN 143:2002, EN 149:2003, EN $405: 2003)$. The general limitation of the regulations is the fact that the IRPD are not required to be tested in the workplace conditions. The direct application of the obtained technical characteristic of respirators in laboratory conditions may result in the errors caused by the influence of various unpredictable factors. The fact is shown in the numerous researches of protective qualities of respirators in the real conditions [3-9]. The results of the researches may be generalized as follows:

a. in case of proper selection of respirator filter the general performance of IRPD is determined only in terms of leakage of unfiltered air through the gaps between the facepiece of a half mask (respirator) and face which is the main way of inhaled air pollution;

b. the gaps are caused by a wide range of factors (improper selection of half mask resulting from not checked fit testing, lack of skills of proper use, stretching of head harness, slacking of clamping force are considered as the most widespread).

The abovementioned issues substantiate the need in workplace respirators tests. But the direct measurement of protective properties of IRPD for accurate assessment of average value of harmful substances concentration reduction in the inhaled air requires multiply tests for each worker. This is expensive and very difficult to be put into practice. One more difficulty is changing leakage level of unfiltered air under the mask. Mask donning and using by workers result in additional variability of IRPD efficiency, as it may be donned incorrectly or slip on the face due to execution of movements. In such cases methods of statistics are widely used to deal with the obtained quantitative data of research results. However, to obtain the accurate value of average protection factor for a particular person in laboratory conditions about 18-25 repeated measures are needed for providing enough random error reducing for statistical analysis [10]. But this is due to execution of similar movements (for certification). Movements may vary in the real conditions, and this results in gaps occurrence. That is the reason for employers not to carry out direct measurements. To choose the proper respirators an employer is obliged to meet the legislation requirements based on the scientific researches [11-15].

The considered issues of IRPD efficiency are applied into the recommendations for employers on IRPD selection in the USA [16]. The recommendations describe the values of predicted protection factors for all IRPD types (obtained by means of statistical analysis of workplace measurements), but it is stated that the values are approximate. It should be also mentioned that the labour safety standards regulating selection and use of IRPD in the USA, Germany and the Great Britain oblige employers to carry out health examinations of employees. In case of some harmful substances ingestion their concentration in biological matrix (blood et al) and metabolic changes may be used for employees' protection assessment. For example, the similar researches were carried out by Petryanov [17] and enabled determination of hazardous concentration boundary for lead in blood for using filtering Lepestok half masks. Later the proper biomonitoring methods for assessment of near 80 harmful substances effect (Biological Exposure Indexes BEI, biological MAC) were developed and have been applied. Biomonitoring enables indirect assessment of general efficiency of measures for protection from harmful substances (including use of IRPD). In the USA employers are obliged to apply biomonotoring while working with lead and Cadmium compounds, and its application is non-mandatory for other harmful substances $[18,19]$. So to reduce the frequency of occupational diseases of respiratory system for workers using ORPD it is important:

a) to specify the air sampling requirements for determination of harmful substances concentration at the workplaces (to carry out sample taking close to worker's face only);

b) to develop sanitary requirements obliging employers to carry out biomonitoring in case of lead and Cadmium effect, as well as other substances with developed efficient methods of effect assessment and biological MAC;

c) to develop the requirements for employers dealing with the proper efficient ORPD selection and implement the substantial trainings based on the findings of modern science

\section{Conclusion}

The analysis of ORPD use efficiency has shown the substantial limitations of quality assessment for respirators. This results in potential hazard of excessive influence of harmful particulate pollutants on employees. To prevent occupational diseases development, it is extremely important that employers are motivated to improve labour conditions. Not least important is development of requirements to the biomonitoring procedure and conditions, as well as selection, testing and users training for IRPD use as based on the modern science development. The elimination of hazard class based only in providing the employees with IRPD is not scientifically substantiated and inadmissible way.

\section{References}

1. Vasiliev EV, Gizatullin ShF, Spelnikova MI (2014) Problem of choice and use of gas and aerosol protecting filtering halfmasks. Guide for labour safety specialist 12: 51-55.

2. Kirillov VA, Filin AS, Chirkin AV (2014) Review of results of industrial tests of individual respiratory protective devices (IRPD). Toxicological Review 6: 44-49.

3. Hewett P, Pallay BG, Gamble JF (1993) A model for correcting workplace protection factors for lung deposition and other effects. American Industrial Hygiene Association Journal 54(4): 142-149.

4. Myers WR, Allender JR, Plummer R, Stobbe T (1986) Parameters that bias the measurement of airborne concentration within a respirator. American Industrial Hygiene Association Journal 47(2): 106-114.

5. Myers WR, Allender JR (1988) Causes of in-facepiece sampling bias--II. full- facepiece respirators. The Annals of Occupational Hygiene 32(3): 361-372.

6. Myers WR, Allende JR, Iskander W, Stanley C (1988) Causes of infacepiece sampling bias--I. half-facepiece respirators. The Annals of Occupational Hygiene 32(3): 345-359. 
7. Liu BYU, Sega K, Rubow KL, Lenhart SW, Myers WR (1984) In-mask aerosol sampling for powered air purifying respirators. American Industrial Hygiene Association Journal 45(4): 278-283.

8. Critical Issues Conference (1988) On in-facepiece sampling. Part 3. Journal of the International Society for Respiratory Protection 6(1): 24 39.

9. Bergman MS, Viscusi DJ, Zhuang Z, Newcomb WE (2013) Evaluation of sampling probes for fit testing N95 filtering facepiece respirators. The Annals of Occupational Hygiene 57(4): 507-518.

10. Krishnan U, Willeke K, Juozaitis A, Myojo T, Talaska G, et al. (1994) Variation in quantitative respirator fit factors due to fluctuations in leak size during fit testing. American Industrial Hygiene Association Journal 55(4): 309-314.

11. British Standards Institution (1997) Guide to implementing an effective respiratory protective device programme. BS 4275:1997 London, UK.

12. US OSHA Standard 29 CFR 1910.134 NIOSH Guide to Industrial Respiratory Protection.
13. Federal Register(2003) Assigned Protection Factors. 68: 34036-34119.

14. Bollinger NJ, Schutz RH (1987) NIOSH Guide to Industrial Respiratory Protection. pp. 87-116.

15. US OSHA Standard 29 CFR 1910.1027 Cadmium 1910.1027(l)-Medical surveillance.

16. Bollinger NJ (2004) NIOSH Respirator Selection Logic.

17. Kaptsov VA, Chirkin AV (2013) Prevention of occupational deceases while using safety mask. Hygiene and sanitation 3: 42-45.

18. US Department of Labor (2001) Respirator usage in private sector firm. pp. 278.

19. Grauvogel LW (1986) Effectiveness of a positive pressure respirator for controlling lead exposure in acid storage battery manufacturing. American Industrial Hygiene Association Journal 47(2): 144-146.

For possible submissions Click below: 